\title{
Laser Annealing of Amorphous Silicon Core Optical Fibers
}

\author{
N. Healy ${ }^{1}$ *, S. Mailis ${ }^{1}$, T. D. Day ${ }^{2}$, P. J. A. Sazio ${ }^{1}$, J. V. Badding ${ }^{2}$ \\ and A. C. Peacock ${ }^{1}$ \\ ${ }^{1}$ Optoelectronics Research Centre, University of Southampton, Southampton, SO17 1BJ, UK \\ ${ }^{2}$ Department of Chemistry and Materials Research Institute, Pennsylvania State University, 16802 PA, USA \\ nvh@orc.soton.ac.uk
}

\begin{abstract}
Laser annealing of an optical fiber with an amorphous silicon core is demonstrated. The annealing process produces a fiber that has a highly crystalline core, whilst reducing the optical transmission losses by $\sim 3$ orders of magnitude.
\end{abstract}

OCIS codes: (160.2290) Fiber materials; (160.6000) Semiconductor materials.

\section{Introduction}

The integration of silicon into optical fibers is an incipient technology that provides a geometrically standardized platform for complex signal processing and enhanced optical frequency generation. A number of methods have been proposed to fabricate silicon optical fibers [1-2], but one key challenge that remains is to realize low loss fibers with small $\sim 1 \mu \mathrm{m}$ scale crystalline cores which are desirable for use in nonlinear optical applications.

In this paper we investigate laser annealing as a method of converting small core amorphous silicon optical fibers to low loss crystalline core fibers.

\section{Experiment}

Silica clad amorphous silicon (a-Si) optical fibers with core diameters of $1.7 \mu \mathrm{m}$ were fabricated using the high pressure microfluidic chemical deposition technique [1]. From the resulting fibers, one batch was annealed using a frequency doubled $\mathrm{Nd}: \mathrm{YVO}_{4}$ Q-switched laser $(532 \mathrm{~nm}, 10 \mathrm{~ns}, 20 \mathrm{~Hz}, 10 \mathrm{~kW}$ peak) and a second batch was annealed using all of the emission lines from a CW argon ion laser (4 W avg.).

The annealed fibers were analyzed by taking Raman spectra at three positions (A, B, C) across the core as labeled in Fig. 1(a). When the fibers are irradiated with the pulsed source, only a localized region at the surface $(\sim 200 \mathrm{~nm})$ has been annealed to a highly crystalline state, as seen in Fig. 1(b). However, fibers irradiated with the CW source can be uniformly annealed across the entire cross-section, as in Fig. 1(c). The dissimilarity between the annealing profiles is due to a reduced thermal diffusion length when annealing with the pulsed laser.

Comparing a Voigt fit to the Raman spectrum of the annealed fiber (using CW) to that of a single crystal reference, Fig. 1(d), shows that they both have a Lorentzian component with a linewidth of $2.7 \mathrm{~cm}^{-1}$, indicating a highly crystalline fiber core. The downshifted peak from $521 \mathrm{~cm}^{-1}$ to $516 \mathrm{~cm}^{-1}$ is a consequence of a residual 'quenching' stress associated with the thermal expansion coefficient mismatch between the cladding and the core.

Using the cutback method, the optical transmission losses of the as deposited a-Si fiber and the annealed fiber (CW source) were determined to be $35.2 \mathrm{~dB} / \mathrm{cm}$ and $5.6 \mathrm{~dB} / \mathrm{cm}$, respectively, at $1550 \mathrm{~nm}$. The loss measured for the annealed fiber represents the lowest loss to date for a crystalline silicon optical fiber with a sub-micron radius core.
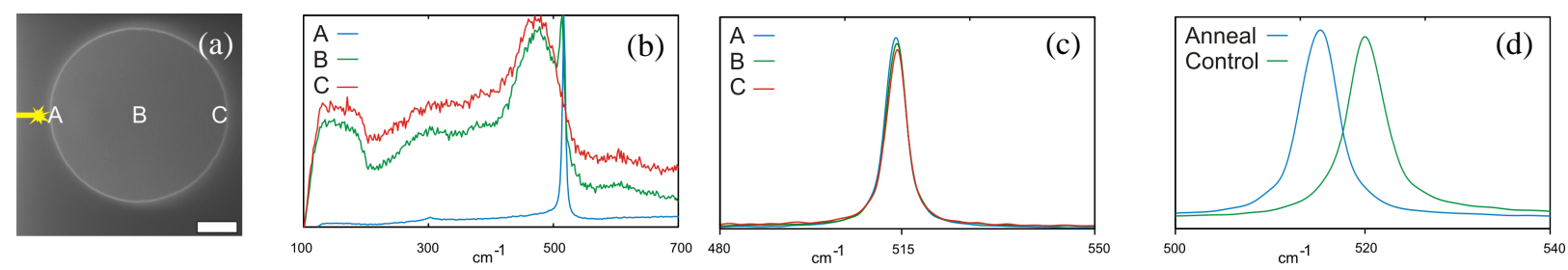

Fig. 1. (a) Measurement positions, direction of irradiation indicated by yellow arrowhead. The Raman spectra of the silicon optical fibers annealed via (b) pulsed laser irradiation (c) CW irradiation. (d) A comparison between the annealed fiber in (c) and the single crystal reference.

\section{References}

[1] L. Lagonigro, N. Healy, J. R. Sparks, N. F. Baril, P. J. A. Sazio, J. V. Badding, and A. C. Peacock, "Low loss silicon fibers for photonics applications," Appl. Phys. Lett. 96, 041105 (2010).

[2] J. Ballato, T. Hawkins, P. Foy, R. Stolen, B. Kokuoz, M. Ellison, C. McMillen, J. Reppert, A. M. Rao, M. Daw, S. R. Sharma, R. Shori, O. Stafsudd, R. R. Rice, and D. R. Powers, "Silicon optical fiber," Opt. Express 16, 18675-18683 (2008). 